\title{
Sustainable Optimal Strategic Planning for Shale Water Management
}

\author{
Alba Carrero-Parreño ${ }^{\mathrm{a}}$, Rubén Ruiz-Femenia ${ }^{\mathrm{a}, \mathrm{b}}$, José A. Caballero ${ }^{\mathrm{a}, \mathrm{b}}$, Juan A. \\ Reyes-Labarta ${ }^{\mathrm{a}, \mathrm{b}}$, Ignacio E. Grossmann ${ }^{\mathrm{c}}$ \\ ${ }^{a}$ Institute of Chemical Process Engineering and ${ }^{b}$ Department of Chemical Engineering, \\ University of Alicante, Ap. Correos 99, Alicante 03080, Spain \\ ${ }^{c}$ Department of Chemical Engineering, Carnegie Mellon University, Pittsburgh, PA 15213, \\ U.S.A.
}

\begin{abstract}
In this work, we introduce a non-convex MINLP optimization model for water management in shale gas production. The superstructure includes: reuse/recycle in the same or neighboring wellpad, treatment in mobile units or in centralized water treatment (CWT) facility, or transport to Class II disposal wells. We consider four different water qualities: flowback water, impaired water, desalinated water and freshwater. Additionally, water blending ratios are unrestricted and friction reducers expenses are calculated accounting for impaired water contamination. The objective is to optimize the fracturing schedule, the number of tanks needed in each time period, flowback destination (reuse, treated or disposal), and fracturing fluid composition by maximizing the "sustainability profit" (Zore et al., 2017). The problem is tackled in two steps. First, we solve an MILP model based on McCormick relaxations. Second, a smaller MINLP is solved in which some binary variables are fixed. The capabilities of the proposed mathematical model are validated against long-time horizon scenario from historical data of the Marcellus Shale play.
\end{abstract}

Keywords: shale gas, water management, sustainability profit, optimization, mixedinteger nonlinear programming

\section{Introduction}

The development of new additives in the shale gas industry, which tolerate the use of high Total Dissolved Solids (TDS) base fluid, has allowed reusing the wastewater in the drilling of subsequent wells (U.S. Environmental Protection Agency, 2016). This practice is currently the most popular and cost-effective option for shale gas water management. Although it minimizes freshwater consumption, producers should take into consideration possible long-term issues and challenges. For instance, the TDS concentration will increase significantly, around 2-3 times, which can represent a cost barrier to reuse the water for fracturing operations. Besides, as the number of drilled wells decrease this practice becomes less attractive. Specifically, the volume of fracturing fluid required to fracture new wells may be less than the volume of water generated by producing wells in the area.

Currently, several works have been reported on the optimization of shale gas water management (Gao and You, 2015; Yang et al., 2015; Lira-Barragán et al., 2016). However, most of the works published in the literature consider that the water blending ratio is restricted or the return to pad operations are not allowed. Drouven and Grossmann 
(2017) assume that the water-blending ratio is unrestricted, they over-estimate the friction reducers expenses. The MILP model that they proposed does not account the salt concentration of impaired water. Moreover, they only distinguish between two types of water: impaired water and freshwater. Hence, the model cannot handle any water management option when drilling operation decrease.

In this work, we propose a mixed-integer non-linear programming (MINLP) model considering the TDS concentration of wastewater and different water treatment solutions. We estimate the friction reducers expenses as a function of TDS concentration to determine if the level of TDS in impaired water is an impediment to reusing it in fracturing operations. Moreover, the model distinguishes between four types of water: impaired water, flowback water, desalinated water and freshwater. The objective is to maximize the "sustainability profit" in order to obtain a compromise solution between economic, environmental and social aspects. Only a single objective function is necessary since all the indicators are expressed in monetary terms (Zore et al., 2017).

\section{Problem statement}

The superstructure proposed for water management in shale gas operations is shown in Figure 1. The water management system comprises wellpads p, shale gas wells in each wellpad w, centralized water treatment technologies (CWT) k, freshwater sources f, fracturing crews $\mathrm{c}$, and disposals wells $\mathrm{d}$.

After hydraulic fracturing, a portion of water called flowback water returns to the wellhead. The flowback water is stored in fracturing tanks (FT) onsite before basic treatment (pre-treatment) in mobile units or transport to CWT facility, Class II disposal or neighboring wellpad. Pre-treatment includes technologies to remove suspended solids, oil and grease, and bacteria, certain ions that can cause the scale to form on equipment and interfere with fracturing chemical additives. After pre-treatment, the water can be used as a fracturing fluid in the same wellpad, or can be desalinated in the onsite TDS removal technologies. The flowback water reused for fracturing operations is called impaired water. Several desalination technologies can be selected such as multi-stage membrane distillation (MSMD), multi-effect evaporation with mechanical vapor recompression (MEE-MVR) or forward-reverse osmosis (FO-RO) hybrid. We consider that the outflow brine salinity in the onsite treatment is close to salt saturation conditions to achieve zero liquid discharge (ZLD) operation. Cost and salinity levels restrict the type of desalination unit that can be used for TDS removal. The onsite desalinated water can also be used as a fracturing fluid in the same wellpad, transported to the next wellpad or discharge for other usages. The flowback water can also be transported and treated in CWT plants. Desalinated water from CWT plants can select the same routes as the desalinated water in onsite technologies. Natural freshwater is obtained from an uninterruptible fresh water source. Desalinated water and freshwater are stored in freshwater tanks (FWT) and/or water impoundment. Transportation of freshwater, impaired water, flowback water and desalinated water can only be through trucks. Storage tanks and mobile treatment are assumed to be leased.

The problem is to determine: (1) wellpad fracturing start date (fracturing schedule), (2) number of tanks leased at each time period, (3) number of trucks needed in each time period, (4) flowback destination, reuse (impaired water), treatment (onsite or offsite) or disposal, and (5) quality of water used to fracture each well. 


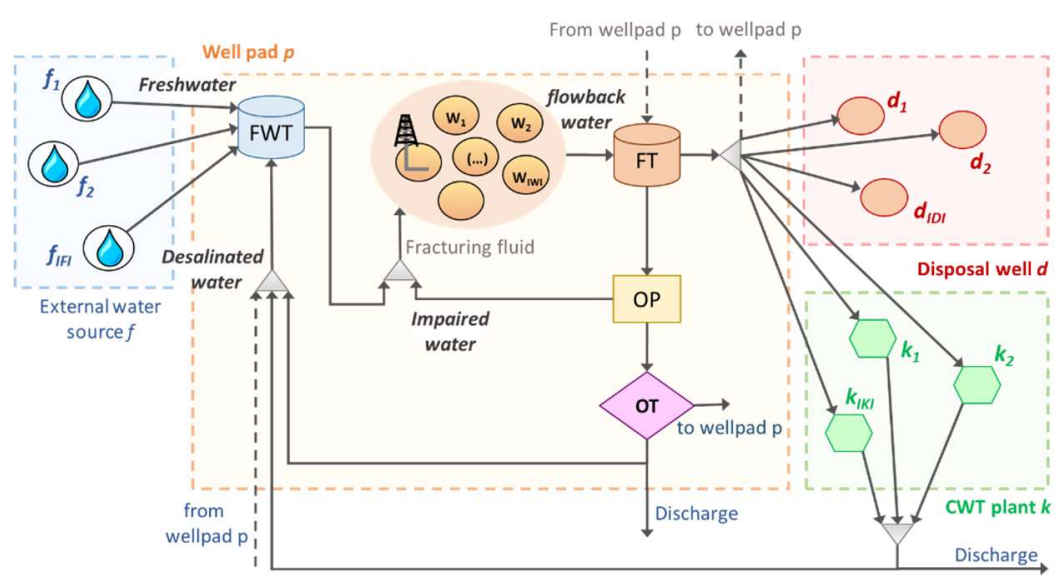

FWT: Freshwater tank /FT: Fracturing tank /OP: Onsite pre-treatment /OT: Onsite treatment

Figure 1. General superstructure of shale gas water management operations

\section{Problem formulation}

The optimization problem is formulated as an MINLP model that includes: assignment constraints, material balance in storage tanks, mixer and splitters, logic constraints and an objective function. Salt material balances are modeled using total flows and salt composition as variables (bilinear terms). An advantage of using this representation is that the variables involved in the bilinear terms are well bounded, allowing us to define tight under and over estimators. A brief outline of some of these equations is next given.

\subsection{Assignment constraints}

Eq. (1) ensures that in each time period only one well can be fractured by one of the available fracturing c. $y_{t, p, w, c}^{h f}$ indicates the beginning of stimulating each well.

$\sum_{t \in T} \sum_{c \in C} y_{t, p, w, c}^{h f} \leq 1 \quad \forall w \in W, p \in R P W$

Eq. (2) guarantees there is no overlap in the hydraulic fracturing operations between different wells. $\tau_{w}^{h f}$ is the time required to fracture well $\mathrm{w}$ with fracturing crew c.

$$
\sum_{p \in R P W} \sum_{w \in W} \sum_{t t=t-\tau_{w, c}^{h f}+1}^{t} y_{t t, p, w, c}^{h f} \leq 1 \quad \forall t \in T, c \in C
$$

\subsection{Storage balance}

Flowback water, impaired water and freshwater is storage in portable leased tanks at a wellpad. Eq. (3) describes the storage balance of tank $s$ in wellpad $p$ in time period $t$.

$n_{t, p, s}=n_{t-1, p, s}+n_{t, p, s}^{i n s}-n_{t, p, s}^{\text {unins }} \quad \forall t \in T, p \in P, s \in S$,

where $n_{t, p, s}$ is a total number of tanks, $n_{t, p, s}^{\text {ins }}$ and $n_{t, p, s}^{\text {unins }}$ represents the number of tanks installed or uninstalled in a specific time period.

The amount of water stored $S T_{t, p, s}$ is bounded by the capacity of one tank $C S T_{S}$ and the number of tanks installed. As time is discretized into weeks, the storage tank should 
handle the inlet water that comes from one day. Therefore, $\theta_{t, p, s}$ represents the inlet water in the storage tank divided by the number of days in a week.

$$
\begin{aligned}
& S T_{t, p, s}+\theta_{t, p, s} \leq C S T_{s} \cdot n_{t, p, s} \quad \forall t \in T, p \in P, s \in S \\
& y_{t, p, s}^{s t} \cdot N_{s}^{L O} \leq n_{t, p, s}^{i n s} \leq N_{s}^{U P} \cdot y_{t, p, s}^{s t} \quad \forall t \in T, p \in P, s \in S
\end{aligned}
$$

$N_{s}^{L O}$ and $N_{s}^{U P}$ are lower and upper bounds of a number of tanks installed. $y_{t, p, s}^{s t}$ indicates the occurrence of installation tanks for each tank $s$ at each time period $t$.

\subsection{Objective function}

The objective function to be maximized is defined as the sum of economic profit $\left(P^{\text {Economic }}\right)$, eco-profit $\left(P^{E c o}\right)$ and social profit $\left(P^{\text {Social }}\right)$.

$\max S P=P^{\text {Economic }}+P^{E c o}+P^{\text {Social }}$

Economic profit includes revenues from natural gas minus the sum of the following expenses: wastewater disposal cost, storage tank cost, freshwater cost, friction reducer cost, wastewater and freshwater transport cost and onsite and offsite treatment cost.

Eco-profit distinguishes between eco-benefit (raw material and products that unburden the environment) and eco-cost (raw material al products that burden the environment). Both terms are calculated by using eco-cost coefficients (Delft University of Technology, 2017). In our problem, impaired water and desalinated water used to fracture a neighboring well exhibit unburdening effect on the environment. However, natural gas, freshwater withdrawal, disposal and transportation burden the environment.

Social profit includes social security contributions paid for the employed people to fracture a well, plus the social transfer by hiring people, minus social cost. We only take into account the numbers of jobs on a fracturing crew and the time that they are working to fracture a specific well. Once the well is completed, the number of jobs generated by truck drivers or maintenance team are not considered.

\section{Case study}

The proposed model is applied to a case study in Marcellus Play with 3 wellpads and 20 wells, one years discretized at one week per time period, four interruptible sources of fresh water, three class II disposal wells, two CWT plants and one fracturing crew.

The MINLP problem consists of 3,117 binary variables, 13,463 continues variables and 10,297 constraints. In order to treat the presence of bilinear terms, which are non-convex, we apply the following decomposition strategy:

- The original MINLP is relaxed using under and over estimators (McCormick convex envelopes), obtaining an MILP. The solution of this problem yields an upper bound (UB) to the MINLP.

- The binary variables which determine the fracture schedule $\left(y_{t, p, w, c}^{h f}\right)$ are fixed into the original MINLP, resulting in a smaller MINLP.

The model is implemented in GAMS 25.0.1. The relaxed MILP problem is solved with Gurobi 7.5.2 and the MINLP problem with DICOPT 2 using CONOPT 4 to solve the 
NLP sub-problems. Although DICOPT cannot guarantee a global solution, we calculate the optimality gap to obtain the deviation of this solution with respect to the global optimum. The decomposition strategy applied for bilinear non-convex MINLP models solves the problem within $0.1 \%$ optimality gap in 1904 CPUs.

The sustainable profit of the optimal solution is equal to $\mathrm{k} \$ 767$, where the economic profit and social profit are equal to $\mathrm{k} \$ 16,910$, and $\mathrm{k} \$ 1,469$ million, respectively. However, the eco-profit component is negative equal to $\mathrm{k} \$-17,611$.

The solution of the model shows that the capabilities to reuse impaired water to fracture other wells is the best economic and environmental practice for shale gas water management. Figure 2 displays the fracturing schedule for each wellpad. The producer would spend $\mathrm{k} \$ 171$ on tolerant additives. Overestimating the price of the friction reducers this cost would rise to $\mathrm{k} \$ 270$, decreasing the total profit to $\mathrm{k} \$ 668$. It is important to highlight that in Marcellus play, only $10-40 \%$ of the water injected is recovered. For that reason, although $92,700 \mathrm{~m}^{3}$ are recirculated, 124,300 $\mathrm{m}^{3}$ of fresh water are still necessary to complete all candidate wellpads.

The solution also provides an effective storage water management strategy to minimize the total storage cost and maximize the impaired water. We consider that operators lease fracturing tanks with $60 \mathrm{~m}^{3}$ of capacity. The total cost of storage is equal to $\$ 363,000$. Figure 3 (a) shows the number of tanks required in each wellpad along time horizon. Figure 3 (b) displays the blending ratio - impaired water used compared to water demand required to fracture each well - over the time.

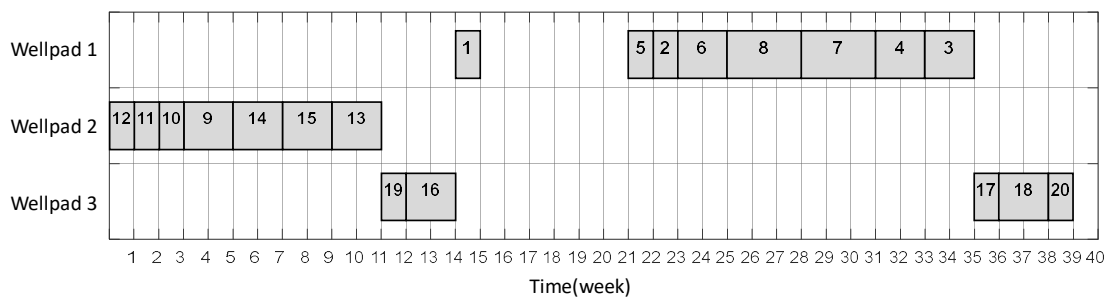

Figure 2. Fracturing schedule.

As commented in the introduction section, it is important to figure out the water management option when all candidates' wells are completed. The practice selected by the model is desalinate the water onsite using membrane distillation treatment. Finally, although transportation cost decreases reusing the wastewater, it still represents a high contribution to the final water management cost equal to $\$ 806,000$.

\section{Conclusion}

An MINLP model has been proposed for economic and environmental decisions in shale gas water management. The new measure expressed in monetary value helps the producers to make sustainable, viable and economic decisions. The model, which can be effectively solved with the proposed decomposition technique, reveals that the level of TDS in impaired water is not an obstacle to reusing it for fracturing purposes. Also, it has been shown that onsite desalination treatment can be cost-effective for operators once no more wells to fracture are available. Further development of this work includes the 
analysis of different sources of uncertainty of some inlet parameters as gas and wastewater production.

a)
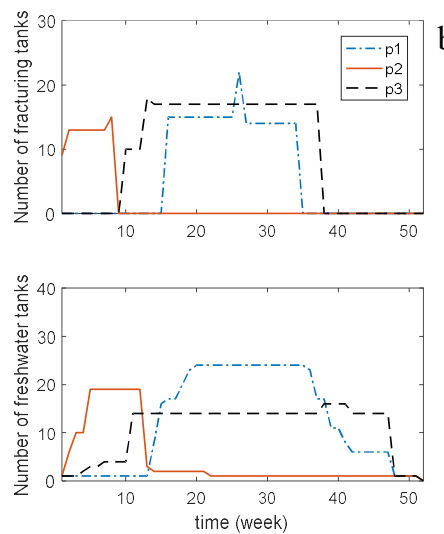

b)

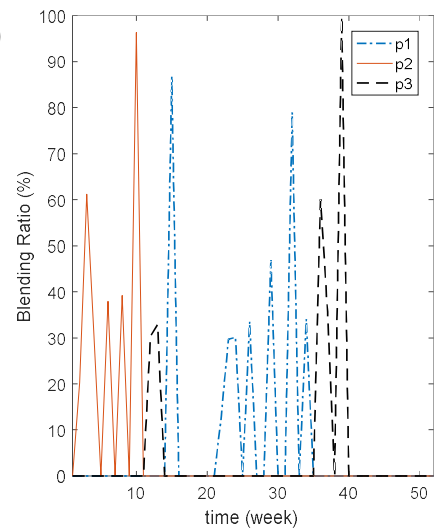

Figure 3. Results for the case study: a) Number of fracturing tanks (FT) and freshwater tanks (FWT) and b) Blending ratio over time for each wellpad.

\section{Acknowledgements}

This project has received funding from the European Union's Horizon 2020 Research and Innovation Program under grant agreement No. 640979 and from the Spanish «Ministerio de Economía, Industria y Competitividad» CTQ2016-77968-C3-02P (FEDER, UE).

\section{References}

Delft University of Technology, 2017. The Model of the Eco-costs/Value Ratio (EVR). URL http://www.ecocostsvalue.com (accessed 12.1.17).

Drouven, M.G., Grossmann, I.E., 2017. Optimization models for impaired water management in active shale gas development areas. J. Pet. Sci. Eng. 156, 983-995.

Gao, J., You, F., 2015. Shale Gas Supply Chain Design and Operations toward Better Economic and Life Cycle Environmental Performance: MINLP Model and Global Optimization Algorithm. ACS Sustain. Chem. Eng. 3, 1282-1291.

Lira-Barragán LF, Ponce-Ortega JM, Serna-González M, El-Halwagi MM. Optimal Reuse of Flowback Wastewater in Hydraulic Fracturing Including Seasonal and Environmental Constraints. AIChE J. 2016;62(5).

U.S. EPA, 2016. Technical Development Document For Effluent Limitations Guidelines and Standars for the Oil and Gas Extraction Point Source Category. Washington, DC.

Yang, L., Grossmann, I.E., Mauter, M.S., Dilmore, R.M., 2015. Investment optimization model for freshwater acquisition and wastewater handling in shale gas production. AIChE J. 61, 17701782.

Zore, Ž., Čuček, L., Kravanja, Z., 2017. Syntheses of sustainable supply networks with a new composite criterion - Sustainability profit. Comput. Chem. Eng. 102, 139-155. 